Phân loại PI-RADS có độ nhạy, độ đặc hiệu, giá trị dự báo dương tính, giá trị dự báo âm tính trong chẩn đoán UT TTL trong nghiên cứu của chúng tôi với PR4 hay PR5 đều là $100 \%$. Theo nghiên cứu của Kim và cộng sự (2021), phân loại PR4 và $P R 5$ có độ nhạy là $93,2 \%$ và $88,3 \%$, độ đặc hiệu là $52,8 \%$ và $76,6 \%$, giá trị dự báo dương tính là $48,7 \%$ và $64,5 \%$, giá trị dự báo âm tính là $65,9 \%$ và $80,4 \%$; thấp hơn so với nghiên cứu của chúng tôi, có thể là do nghiên cứu này có số lượng mẫu (317 tổn thương) lớn hơn rất nhiều so với nghiên cứu của chúng tôi (10 tổn thương).

\section{KẾT LUẦN}

Qua nghiên cứu, chúng tôi nhận thấy phân loại PI-RADS trên cộng hưởng từ có độ nhạy và độ đặc hiệu rất cao với các tổn thương khu trú trong chẩn đoán ung thư tuyến tiền liệt.

\section{TÀI LIẸU THAM KHẢO}

1. Torre LA, Bray F, Siegel RL, Ferlay J, LortetTieulent J, Jemal A. Global cancer statistics, 2012. CA Cancer J Clin. 2015;65(2):87-108. doi:10.3322/caac.21262

2. Van Dong $\mathrm{H}$, Lee AH, Nga $\mathbf{N H}$, Quang $\mathbf{N}$, Le Chuyen $\mathbf{V}$, Binns $\mathbf{C W}$. Epidemiology and prevention of prostate cancer in Vietnam. Asian Pac J Cancer Prev. 2014;15(22):9747-9751. doi:10.7314/apjcp.2014.15.22.9747
3. Murphy G, Haider M, Ghai S, Sreeharsha B. The expanding role of MRI in prostate cancer. AJR Am J Roentgenol. 2013;201(6):1229-1238. doi:10.2214/AJR.12.10178

4. Ahmed HU, Kirkham A, Arya M, et al. Is it time to consider a role for MRI before prostate biopsy? Nat Rev Clin Oncol. 2009;6(4):197-206. doi:10.1038/nrclinonc.2009.18

5. Tamada $\mathbf{T}$, Sone $\mathbf{T}$, Higashi $\mathbf{H}$, et al. Prostate cancer detection in patients with total serum prostate-specific antigen levels of $4-10 \mathrm{ng} / \mathrm{mL}$ : diagnostic efficacy of diffusion-weighted imaging, dynamic contrast-enhanced MRI, and T2-weighted imaging. AJR Am J Roentgenol. 2011;197(3):664670. doi:10.2214/AJR.10.5923

6. Barentsz JO, Richenberg J, Clements R, et al. ESUR prostate MR guidelines 2012 . Eur Radiol. 2012;22(4):746-757.doi:10.1007/s00330-011-2377-y

7. Weinreb JC, Barentsz JO, Choyke PL, et al. PI-RADS Prostate Imaging - Reporting and Data System: 2015, Version 2. Eur Urol. 2016;69(1):1640. doi:10.1016/j.eururo.2015.08.052

8. Vũ Lê Chuyên, Đố Anh Toàn. Khảo sát tỷ lệ ung thư tuyến tiên liêt ở nam giới trên 50 tuổi đến khám tại bệnh viện Bình Dân. Y Học TP Hồ Chí Minh. 2012;16:335-341.

9. Vũ Trung Kiên, Đố Trường Thành, Nguyễn Lan Hương. Đánh giá kết quả sinh thiết tuyến tiền liêt 12 mâuu trong chẩn đoán sớm ung thư tuyến tiền liệt. Tap chí Y dược học - Trường Đạ hoc Y Dược Huế. 2017; Số đặc biệt tháng 8/2017:297-303.

10. Trịnh Lê Hồng Minh. Giá trị của cộng hưởng từ khuếch tán trong chẩn đoán ung thư biểu mô tuyến tiền liệt. Published online 2014.

\title{
HIỆU QUẢ TÁI KHOÁNG HOÁ CỦA VÉC-NI ENAMELAST 22,6mg FLORUA TRÊN TỔN THƯƠNG KHỬ KHOÁNG MEN RĂNG VĨNH VIỄN TRONG THỰC NGHIỆM
}

\section{TÓM TẮT}

Véc-ni fluor được phát triển và đưa ra thị trường dưới dang sodium fluor vào cuối những năm 1960 (Duraphat - Colgate) và trong những năm 1970 dưới dang silane fluor (Fluor Protector - Ivoclar Vivadent), những năm 1980 được sử dụng rộng rãi tại Châu Âu. Véc-ni fluor được chứng minh là biên pháp dư phòng và điều trị sâu răng tại chố có nhiều ưu điểm, được khuyến cáo sử dụng cho trẻ em. Nghiên cứu được tiến

${ }^{1}$ Viện nghiên cứu Khoa học Y Dược Lâm sàng 108

${ }^{2}$ Trường Đại học Kỹ thuật $Y$ - Dược Đà Nẵng

${ }^{3}$ Bênh viện Trung ương Quân đội 108

${ }^{4}$ Trường Đại hoc Y Dược - Đại học Quốc gia Hà Nội.

Chịu trách nhiểm chính: Nguyễn Mạnh Cường

Email: dr.manhcuong@gmail.com

Ngày nhận bài: 17.5.2021

Ngày phản biên khoa hoc: 6.7.2021

Ngày duyệt bài: 16.7.2021 hành trên 60 răng vĩnh viễn, các răng 4 - 5 (răng hàm nhỏ vĩnh viễn thứ nhất và thứ hai) được nhổ đế chỉnh nha, tuổi của các bênh nhân nhổ từ 18-25 nhằm muc tiêu: mô tả quá trình khoáng hóa của fluor trong vécni vào men răng vĩnh viễn. Đây là một nghiên cứu invitro-nghiên cứu thực nghiệm trong phòng thí nghiệm can thiệp có đổi chứng nhằm xác định những bằng chứng ngấm fluor vào men về mặt mô học và mô tả hình thái dưới kính hiển vi điên tử quét. Các răng vĩnh viễn ngay sau khi nhổ được ngâm trong nước bọt nhân tạo, được vệ sinh sạch, lấy bỏ hết tỗ chức phân mềm còn dính trên thân răng chân răng, đánh bóng bằng chổi cước làm sach mảng bám và khử khoáng bằng axit photphoric $37 \%$ trong 15 giây. Sau đó các răng được chia thành 2 nhóm: một nhóm được bôi véc-ni Enamelast 22,6 mg florua trong 4 phút, nhóm còn lại được chải kem đánh răng Colgate Kids. Các răng được chuyển cắt làm tiêu bản và được mô tả hình thái dưới kính hiển vi điện tử quét. Kết quả cho thấy răng sau khử khoáng bằng axit photphoric 
37\% trong 15 giây gây tổn thương sâu răng sớm mức D1 tương đương sâu răng ICDAS mã số 1 và véc-ni Enamelast 22,6mg florua có tác dụng tái khoáng hóa tốt tổn thương khử khoáng men răng vĩnh viễn trên thực nghiệm. Từ kết quả này có thể đưa ra khuyến cáo: véc-ni fluor là một lựa chọn tốt trong dự phòng và điều tri sâu răng.

Tư khóa: khử khoáng, tái khoáng men răng, vécni fluor.

\section{SUMMARY \\ REMINERALIZATION EFFICIENCY OF 5\% FLUORIDE VARNISH IN DEMINERALIZATION LESIONS OF ENAMEL IN PERMANANT TEETH: AN IN VITRO STUDY}

Fluoride varnish has been proved to be a preventive tool and local treatment method for dental caries with many advantages; the use of fluoride varnish has been recommended for children, especially small children. Fluoride varnish has been used world wide including Viet Nam. The study was conducted on 60 permanent teeth, teeth 4 - 5 (first and second permanent premolars) were extracted for orthodontic treatment, the age of the patients was extracted from 18-25 with the objectives: to describe the process of mineralization of fluoride in fluoride varnish into the permenant teeth enamel. This is an in vitro study which is the experiment study being done in the laboratory. After being extracted, the permenant teeth were soaked in artificial saliva, cleaned until plaque-free and demineralized with $37 \%$ phosphoric acid for 15 seconds. The teeth were then devided into two group: in the first group, the teeth were applied with $5 \%$ fluoride varnish for 4 minutes, in the second group, the teeth were brushed with Colgate Kids toothpaste for children. All the teeth were sectioned to make samples then were examined under scanning electron microscopy (SEM). Results showed the process of demineralization using $37 \%$ phosphoric acid for 15 seconds caused early carious lesions grade D1 that is equal to carios lesions code 1 in ICDA system. From the study result, we recommended that the use of fluoride varnish is a good choice in prevention and treatment of early caries of permenant teeth in children.

Keyword: demineralization, enamel remineralization in permenant teeth, fluoride varnish

\section{I. ĐĂT VẤN ĐỀ}

Véc-ni fluor ra đời như là một công cụ hữu hiệu bảo vệ răng, giúp răng giảm nguy cơ bị sâu, đồng thời tái khoáng hóa và sửa chữa hoàn nguyên lại tổ chức men răng bị tổn thương ngay từ giai đoạn sớm mà không cần can thiệp khoan răng, ngoài ra fluor còn tác động làm chậm lại quá trình tiến triển của sâu răng.

Các tác dụng quan trọng nhất của sản phẩm chăm sóc răng miệng có Fluor bao gồm tăng cường khoáng hóa của men răng và bảo vệ chống lại sự hủy khoáng men răng. Ngoài ra có một số nghiên cứu cho thấy nồng độ ion Fluor ảnh hưởng đến việc sản xuất axit nội bào và bài tiết proton trong Streptococcus mutans; nghiên cứu của Marinho VC và cộng sự, qua phân tích tổng hợp các nghiên cứu can thiệp bằng véc-ni fluor thấy véc-ni fluor làm giảm sâu răng là 33\% (95\%CI, 19\% - 46\%) [1].

Trên thế giới các nghiên cứu về véc -ni fluor đã tập trung làm rõ cơ chế tác dụng, hiệu quả phòng và điêu trị sâu răng, liều lượng và cách dùng... của các dạng véc-ni fluor khác nhau. Tuy nhiên những nghiên cứu này vẫn còn nhiều hạn chế như chưa đưa ra được một phương pháp hoàn hảo (hiệu quả cao, an toàn, đơn giản khi sử dụng), chưa tìm ra liều lượng tối ưu cho các giai đoạn của tổn thương sâu răng [2]. Tại Việt Nam đến nay mặc dù có rất nhiêu công trình nghiên cứu về sâu răng ở tất cả các lứa tuổi song đa số những nghiên cứu này mới chỉ dừng lại ở việc chẩn đoán được sâu răng ở các giai đoạn muộn, vì vậy việc phòng và điều trị bệnh cho hiệu quả còn thấp. Chưa có nghiên cứu nào về tình trạng sâu răng của trẻ em trong việc sử dụng véc-ni fluor để can thiệp dự phòng và điều trị sâu răng Vì vậy chúng tôi tiến hành nghiên cứu với mục tiêu: "Đánh giá hiệu quả tái khoáng hoá của Véc-ni Enamelast 22,6 mg florua trên tổn thương khử khoáng men răng vĩnh viến trong thực nghiệm".

\section{II. ĐỐI TƯỢNG VÀ PHƯƠNG PHÁP NGHIÊN CỨU 2.1. Đối tượng nghiên cứu thực nghiệm}

Đối tượng nghiên cứu là các rang 4-5 (răng hàm nhỏ vĩnh viễn thứ nhất và thứ hai) được nhổ để chỉnh nha thu thập từ các phòng khám trên địa bàn Hà Nội. Tuổi của các bệnh nhân nhổ từ 18-25.

Tiêu chuẩn lựa chọn: răng không bị sâu vỡ, thân và chân răng còn nguyên vẹn. Quan sát dưới kích lúp thấy lớp men mặt ngoài còn nguyên vẹn. Chỉ số Diagnodent < 13.

Tiêu chuẩn loại trừ: Có vết trắng hoặc đốm nâu trên bề mặt, thiểu sản men, răng bị nhiễm màu tetracycline, răng nhiễm fluor, răng có lỗ sâu chẩn đoán theo ICIDAS, thân hoặc chân răng bị gãy, võ hoă̆c răng có chỉ số Diagnodent > 13 .

\subsection{Thời gian và địa điểm nghiên cứu}

Nghiên cứu được thực hiện từ 1/2019 - tháng 7/2019 tại Khoa Hình thái, Viện 69 - Bộ Tư Lệnh Lăng.

2.3. Phương pháp nghiên cứu. Là nghiên cứu invitro - nghiên cứu thực nghiệm trong phòng thí nghiệm.

2.4. Quy trình tiến hành nghiên cứu

2.4.1. Vật liệu và công cụ thu thập thông tin bao gồm:

- Dụng cụ và vật liệu chuẩn bị mẫu răng: Đĩa 
cắt kim cương kích thước $15 \times 0,1 \mathrm{~mm}$, thiết bị Diagnodent 2190-KaVo (Đức)...

- Dụng cụ và vật liệu trong phòng thí nghiệm: Kính hiển vì điện tử quét, hóa chất (nước bọt nhân tạo, kem chải răng Colgate Kids trẻ em, Véc-ni Enamelast 22,6mg florua...).

\subsubsection{Các bước tiến hành nghiên cứu}

- Bước 1: Chuẩn bị mẫu răng nghiên cứu

- Bước 2: Can thiệp trên mẫu răng: khử khoáng, chải kem hoặc bôi véc-ni,...

- Bước 3: Xử lý mẫu: Khử nước, khử cồn và ma phủ mấu

\subsection{3. Đánh giá kết quả}

- Soi mẫu dưới kính hiển vi điện tử quét JSM 5410LV của Nhât Bản.

- Đánh giá bề mặt thân răng trước và sau khử khoáng, sau chải kem đánh răng và bôi véc-ni Enamelast 22,6 mg florua.

\section{KẾT QUẢ NGHIÊN CỨU}

\subsection{Giá trị Diagnodent trên mẫu nghiên cứu}

Bảng 3.1. Chỉ số Diagnodent của nhóm răng trước và sau khử khoáng

\begin{tabular}{|c|c|c|}
\hline Thời điểm & $\mathbf{n}$ & $\begin{array}{c}\text { Giá trị đo } \\
\text { Diagnodent }\end{array}$ \\
\hline Trước khử khoáng & 60 & $9,6 \pm 2,3$ \\
\hline Sau khử khoáng & 60 & $18,2 \pm 1,3$ \\
\hline
\end{tabular}

Nhận xét: Trước khử khoáng, chỉ số Diagnodent trung bình của nhóm răng trong nghiên cứu là $9,6 \pm 2,3$, là chỉ số nằm trong giới hạn bình thường ( $\leq 13$, răng không bị sâu). Sau khử khoáng, các răng có chỉ số Diagnodent trung bình là $18,2 \pm 1,3$, là chỉ số nằm trong giới hạn sâu răng mức D1 (chỉ số Diagnodent trong khoảng 14-21), tương đương với ICDAS mã số 1 trên lâm sàng.

Bảng 3.2. Chỉ số Diagnodent của hai nhóm sau can thiệp

\begin{tabular}{|c|c|c|}
\hline Nhóm & $\mathbf{n}$ & $\begin{array}{c}\text { Giá trị đo } \\
\text { Diagnodent }\end{array}$ \\
\hline $\begin{array}{c}\text { Bôi Véc-ni Enamelast } \\
22,6 \text { mg florua }\end{array}$ & 30 & $11,7 \pm 1,1$ \\
\hline $\begin{array}{c}\text { Bôi kem chải răng } \\
\text { Colgate Kids }\end{array}$ & 30 & $16,8 \pm 1,0$ \\
\hline
\end{tabular}

Nhận xét: Sau khử khoáng, các răng có chỉ số Diagnodent trung bình của nhóm răng trong nghiên cứu là $18,5 \pm 4,20$, là chỉ số nằm trong giới hạn sâu răng mức D1 (chỉ số Diagnodent trong khoảng 14-21), tương đương với ICDAS mã số 1 trên lâm sàng.sau khi tiến hành can thiệp bôi kem chải răng Colgate Kids thì chỉ sô Diagnodent trung bình của nhóm là $16,8 \pm 1,0$, tương đương mức D1. Còn chỉ số Diagnodent trung bình của nhóm bôi véc-ni Enamelast 22,6 mg florua là $11,7 \pm 1,1$, tương đương mức D0.

\subsection{Một số hình ảnh hiển vi điện tử thân răng vĩnh viễn bình thường và sau khử khoáng}

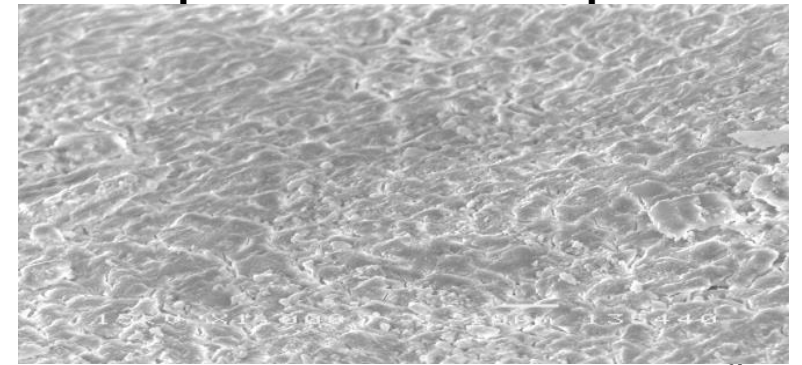

Hình 3.1. Hình ảnh bề mặt răng vĩnh viễn binh thường (x 2000)

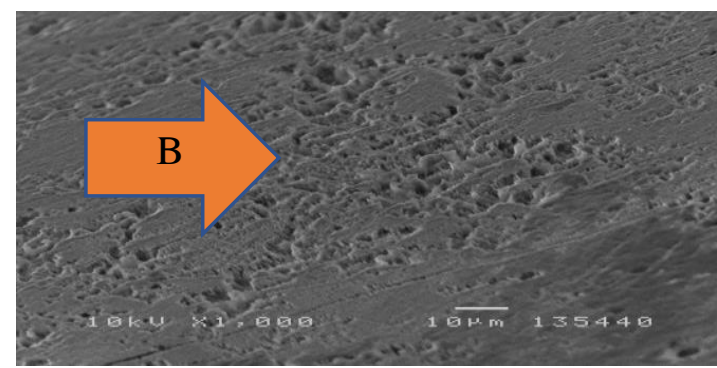

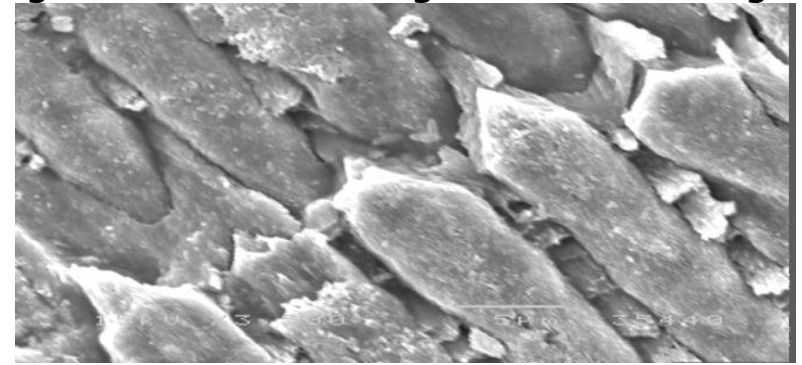

Hình 3.2. Hinh ảnh cắt dọ trụ men binh thường ( $x$ 3500)

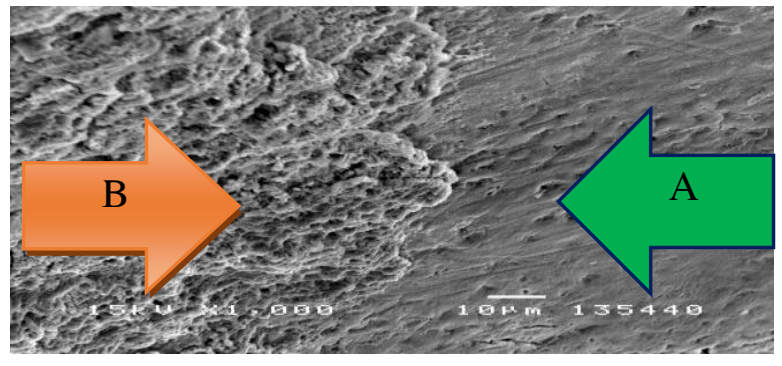

khoáng và ranh giới giữa bình thường và khử khoáng (độ phóng đại x 1000)

Nhận xét: Hình ảnh bề mặt thân răng sữa bình thường là một vùng mịn, đồng nhất và có các điểm tận cùng của trụ men (Hình 3.1). Cắt dọc bề mặt men thân răng cho thấy các trụ men xếp song song 
và khoảng cách giữa các trụ men khá lớn (Hình 3.2). Sau khi bị huỷ khoáng, thấy cấu trúc bề mặt thân răng bị xáo trộn, các trụ men bị phá huỷ cấu trúc và mất khoáng tạo thành những hốc, rãnh, để trơ phần hữu cơ của men răng, hình ảnh cho thây đề mặt men rang giống hình ảnh "súp lơ" (Hình 3.3 - B).

\subsection{Môt số hình ảnh hiển vi điên tử thân răng vĩnh viễn sau tái khoáng}

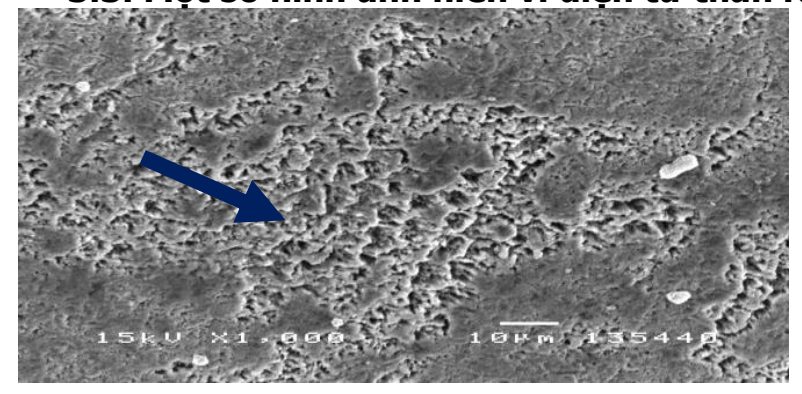

Hình 3.4. Hình ảnh bề mặt thân răng sau chải kem Colgate Kids (x1000)

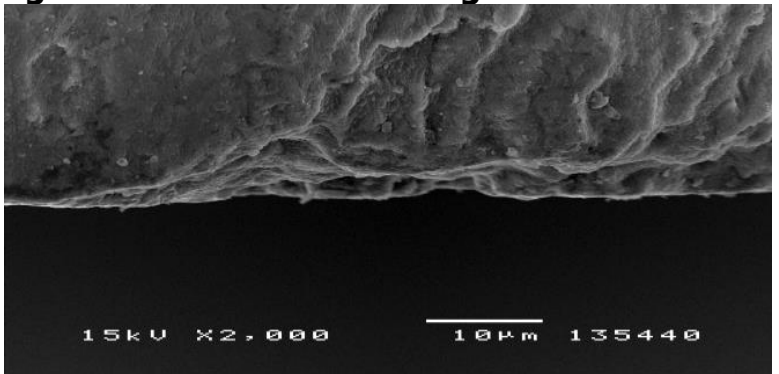

Hình 3.5. Hình ảnh cắt dọ và chupp nghiêng bề mặt thân răng vĩnh viễn sau chải kem Colgate Kids (x2000)

Nhận xét: Sau chải kem đánh răng Colgate Kids, nhiều tinh thể men chưa được tái khoáng hóa, bề mặt men răng vẫn còn nhiều hố, hốc ở độ phóng đại x2000 (Hình 3.4). Hình ảnh chụp nghiêng cắt dọc qua vùng tái khoáng thân răng cho thấy, nhiều trụ men bi phá hủy chưa được tái khoáng. Bề mắt men răng vẫn còn nhiều vùng lỗ chỗ, nham nhở như ngọn "núi lửa" ở độ phóng đại x2000 (Hình 3.5).

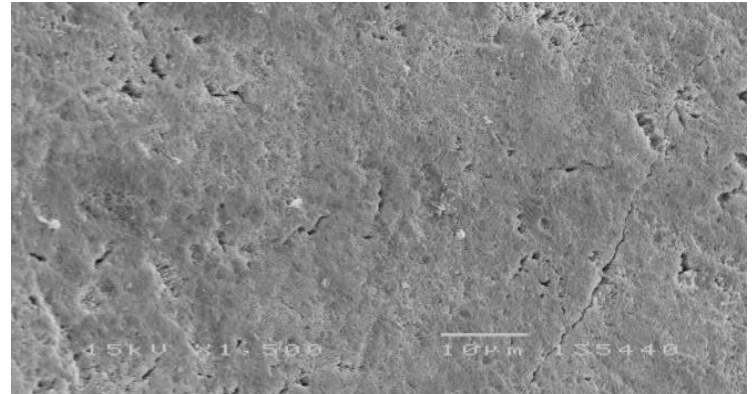

Hình 3.6. Hình ảnh bề mặt răng sau bôi véc-ni Enamelast 22,6 mg florua (x1500) A: Vùng men binh thường $B$ : Vùng men tái khoang

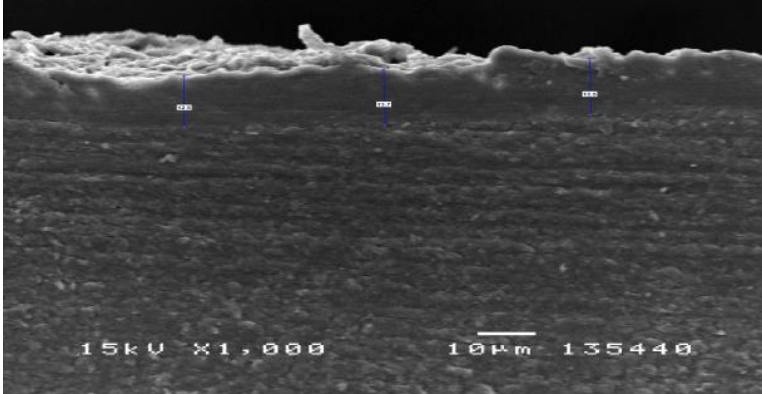

Hình 3.7. Hình ảnh cắt dọc bề mắt thân răng sữa sau bôi véc-ni Enamelast 22,6 mg florua (x1000)

Nhận xét: Sau khi bôi véc-ni fluor, bề mặt men răng vùng khử khoáng trở nên mịn, đồng nhất, không còn thấy các khe, các hốc trên bề mặt men (Hình 3.6). Hình ảnh cắt dọc qua vùng tái khoáng cho thấy các trụ men đã được tái khoáng hóa hoàn toàn ở độ phóng đại x1000 (Hình 3.7).

\section{BÀN LUẬN}

4.1. Giá trị Diagnodent trên mẫu nghiên cứu. Trong phòng thí nghiệm, để tạo được những tổn thương bề mặt men răng giống tổn thương sâu răng trên lâm sàng, một số tác giả đã sử dụng chu trình $\mathrm{pH}$, đây là một phương pháp thực nghiệm cho men răng lành tiếp xúc lần lượt và liên tục với các dung dịch hủy khoáng và tái khoáng, lặp lại trong một khoảng thời gian nhất định tạo thành vòng tròn khép kín. Thời gian tiếp xúc và khoảng cách giữa các chu trình tùy từng tác giả và mục đích nghiên cứu [3].

Tuy nhiên, để thực hiện được chu trình pH cần phải có phòng thí nghiệm với đầy đủ các phương tiện, vật liệu nghiên cứu và một quy trình pha trộn dung dịch hóa chất nghiêm ngặt. Do vậy đòi hỏi nhiều công sức và mất nhiều thời gian thực hiện. Trong nghiên cứu này chúng tôi sử dụng phương pháp hủy khoáng bằng axit phosphoric 37\% trong thời gian 15 giây, tương tự như nghiên cứu của của Hà Ngoc Chiều năm 2019 trên 30 răng người cao tuổi [5], và nghiên cứu của Lưu Văn Tường năm 2018 trên 30 răng sữa [4]. Kết quả cho thấy, trước khử khoáng, giá trị Diagnodent đo được trung bình là 9,6 $\pm 2,3$, tất cả các răng đều bình thường và sau khi khư khoáng, giá trị Diagnodent đo được trung bình là $18,2 \pm 1,3$ (Bảng 3.1), nghĩa là tất cả các răng đều bị sâu răng mức $D 1$, tương đương với mã số sâu răng ICDAS 1 trên lâm sàng. Chỉ số Diagnodent trong nghiên cứu của chúng tôi thấp 
hơn nghiên cứu nghiên cứu cửa Lưu Văn Tường năm 2018 [4] $(25,5 \pm 4,20)$ và cao hơn nghiên cứu của Hà Ngọc Chiều năm $2019(17,6 \pm 3,20)$ [5] có thể là do mẫu răng nghiên cứu. Nghiên cứu của Lưu Văn Tường là trên răng sữa còn trong nghiên cứu của Hà Ngọc Chiều là những răng của người cao tuổi. Đối với răng vĩnh viễn, theo thời gian từ khi răng mọc, quá trình tái khoáng hoá liên tục diễn ra, kết quả là chất khoáng dần lấp đầy các trụ men và khoảng gian trụ men so với răng sữa và răng ở trẻ, vì vậy axit phosphoric sẽ ngấm và phá hủy chất khoáng khó khăn hơn trong quá trình khử khoáng, làm chỉ số Diagnodent khác so với nghiên cứu của chứng tôi.

4.2. Hình ảnh thân răng vĩnh viễn bình thường và sau khử khoáng. Nghiên cứu hình ảnh men răng trên kính hiển vi điện tử quét cho phép đánh giá được sự hủy khoáng thông qua việc quan sát những hình thái đặc trưng và so sánh những đặc điểm cấu trúc của men như: hình thái, kích cõ̃ của các trụ men, hình thái bề mặt men bình thường và sau khi hủy khoáng, hình ảnh bề mặt được tái khoáng...

Hình ảnh bề mặt men răng vĩnh viễn bình thường là một vùng mịn, đồng nhất, không thấy rõ bề mặt các trụ men cũng như ranh giới giữa các trụ men nhưng rải rác có thể thấy các điểm tận cùng của trụ men (Hình 3.1). Cắt dọc bề mă̆t men thân răng sữa cho thấy các trụ men xểp song song và khoảng cách giữa các trụ men khá lớn; giữa các trụ men là khoảng gian trụ, trong thân trụ men có các tinh thể men và chất hữu cơ (Hình 3.2).

Sau khi khử khoáng bằng axit phosphoric $37 \%$ bề mặt thân răng sữa bị xáo trộn, các trụ men bị phá huỷ cấu trúc và mất khoáng tạo thành những hốc, rãnh, để trơ phần hữu cơ của men răng (Hình 3.3 - B). Kết quả này cũng tương tự như kết quả của Sabel N. (2012) và cộng sự [6], nghiên cứu quá trình khử khoáng men rằng sữa và răng vĩnh viễn bằng axit phosphoric trong 30 giây trên SEM. Kết qủa cho thây sau khử khoáng cả men răng sữa và răng vĩnh viễn đều bị phá huỷ cấu trúc, men răng đáp ứng với quá trình khử khoáng với độ sâu tổn thương khác nhau liên quan với thành phần của men răng, các tổn thương sâu hơn khi độ xốp của men răng lớn hơn. Kết quả của chúng tôi cũng tương tự như nghiên cứu của Namrata Patil (2013) [7] và Phạm Thị Hồng Thùy (2014) [3] khi nghiên cứu trên răng vĩnh viễn của trẻ. Cả hai tác giả đều sử dụng chu trình pH để khử khoáng men răng và hình ảnh trên SEM sau khử khoáng đều cho thây các tinh thể men bị mất khoáng, men răng bị phá huỷ cấu trúc tạo thành những vùng sáng tối khác nhau.

4.3. Hiệu quả của véc-ni Enamelast 22,6 mg florua đối với tổn thương mất khoáng

Kết quả nghiên cứu của chúng tôi trên thực nghiệm cho thấy véc-ni Enamelast $22,6 \mathrm{mg}$ florua có tác dụng tái khoáng hóa các tổn thương sâu răng vĩnh viễn sớm trên thực nghiệm. Kết quả này cũng tương tự như nghiên cứu của Praphasri Rirattanapong và cộng sự (2014) tại Thái Lan [8]. Qua nghiên cứu này có thể nhận định có bằng chứng thuyết phục về việc sử dụng véc-ni fluor $5 \%$ điều trị và dự phòng sâu răng, nhất là các tổn thương sâu răng giai đoạn sớm trên lâm sàng.

\section{KẾT LUÂN}

Véc-ni fluor có tác dụng tái khoáng hoá bề mặt men răng trên thực nghiệm: Có hình ảnh tái khoáng hoá bề mặt men răng vĩnh viễn sau huỷ khoáng; Chỉ số Diagnodent giảm từ mức 18,2 \pm 1,3 trước khi bôi (sâu răng mức D1) còn $11,7 \pm$ 1,1 sau khi bôi Véc-ni Enamelast 22,6 mg florua (không sâu răng).

\section{TÀI LIẸU THAM KHẢO}

1. Marinho VC et al (2013). Fluoride varnish for preventing dental caries in children and adolescents. Cochrane Database Syst Rev, CD002280.

2. Debbie Bonetti, Jan E. Clarkson (2016). Fluoride Varnish for Caries Prevention: Efficacy and Implemetation. Caries Res 2016;50(suppl 1): 45-49.

3. Pham Thi Hông Thùy (2014). Đánh giá hiêu quả của GC TOOTH MOUSSE PLUS đối với tổn thương sâu răng giai đoạn sớm trên thực nghiếm tại trường đại học Y Hà Nội năm 2014, Luận văn Thạc sĩ Y học, Trường Đại học Y Hà Nội.

4. Lưu Văn Tường (2018). Đánh giá mức độ tái khoáng hóa men răng cúa gel $\mathrm{NaF} 0,615 \%$ trên thực nghiệm. Tạp chí $Y$ học Thực hành, 802 (1), 50-53.

5. Hà Ngọc Chiêu (2019). Nghiên cứu dự phòng sâu răng bằng gel fluor ở ngưỡi cao tuổi thành phố Hải Phòng, Luận án Tiến sĩ Y học, Trường Đại học Y Hà Nô̂i.

6. Sabel N., Robertson A., Nietzsche S. et all (2012). Demineralization of Enamel in Primary Second Molars Related to Properties of the Enamel. The Scientific World Journal, Article ID 587254, 1-8.

7. Namrata Patil (2013). Comparative evaluation of remineralizing potential of three agents on artificially demineralized human enamel: An An in vitro study. J Conserv Dent, 16(2):116-120.

8. Rirattanapong $P_{\text {, }}$ Vongsavan Saengsirinavin $C$, et al (2014). Effect of fluoride varnishes containing tri-calcium phosphate sources on remineralization of initial primary enamel lesions. Southeast Asian J Trop Med Public Health, 45(2): 499-504. 